Journal of Social Sciences 8 (2): 238-245, 2012

ISSN 1549-3652

(C) 2012 Science Publications

\title{
The Adult Educator of Immigrants as an Intercultural Consultant
}

\author{
Athina A. Sipitanou and Alexandra S. Foukidou \\ Department of Educational and Social Policy, \\ University of Macedonia 156, Egnatia str., P.O. Box 159154006 Thessaloniki, Greece
}

\begin{abstract}
Problem statement: Inspired by this multi-cultural situation in Greece and the need of immigrants for participation in adult education, this article examines an aspect of the Adult Educator who has to develop intercultural techniques in the frame of his role in order to become an Intercultural consultant. Therefore the aim of this study is to examine specific characteristics that define the Adult Educator as an Intercultural Consultant. In this way, the Adult Educator contributes to the smooth functioning of educational and thus socialization process in a multinational class. Approach: We present some statements that are likely to occur during an educational program when the student group is culturally different. In particular we focus on situations that are perceived as challenges by the Adult Educator and also recommend practices and guidelines for facing them. Results: The challenges that the Educator has to repeal, expressed in the student group, from the Educator to group and from the group to Educator. The description of possible situations shows up lingering stereotypes, negative attitudes, difficulties in interpreting multicultural communication styles and conflict. Combining practices which the Educator could apply in similar situations, we end up proposing the revision of views through acquaintance with the "other" culture, empathy, promote parity of relationships, humor and cultivating a climate of cooperation. Conclusion: Consequently the Adult Educator as an Intercultural Consultant can adjust the presence of immigrant student in the classroom and contribute to redefining experiences and perceptions of both-culturally diverse learners and the Educator.
\end{abstract}

Key words: Intercultural consultant, culturally diverse learners, multicultural communication, multicultural situation, unforeseen immigrating, intercultural ability

\section{INTRODUCTION}

In our days when we characterize a country as multicultural we mean that it tends to realize the social changes and to encode the current problems and the social conflicts in terms of political and social institutions, independently from its heterogenic population (Govaris, 2000a). Taking this as granted, the multicultural situation of a country is able to contribute to the penetration of democracy in susceptible social groups, such as immigrants.

Greece, like many other countries in western Europe, has met an unforeseen immigrating current that started in the early 90's and keeps going intense until today, causing a not only multileveled but also keen social issue. In this frame belongs the social care of adult immigrants that came into the country and aim at participating in educational programs that have as purpose the Greek language acquisition.

The viewpoint that we study deals with the Educator that takes part in this kind of programs focusing to the fact that the trained people are conditioned by diverse cultural characteristics. Specifically, we examine the Adult Educator of immigrants to his dimension of Intercultural Consultant that he is called to cover parallel to the other dimensions that his role involves. We penetrate referring to situations that might take place in a department with multicultural complexion and we propose treatments from the Adult Educator using his intercultural ability in the educational framework.

The intercultural character of the adult educator of immigrants: The multidimensional role of the Adult Educator demands by himself, beyond the cognitive object's possession and a range of abilities that respond to the demands of each educational public a time. When the Adult Educator is called to participate in groups where the student audience is conditioned by diverse cultural characteristics, has practically to face situations that toughen up the educational procedure either they come from the educated group or from the educator himself. In this framework he undertakes an advisory and guiding role with the necessary development of a further ability from his place, the intercultural ability that is.

Corresponding Author: Athina A. Sipitanou, Department of Educational and Social Policy, University of Macedonia 156, Egnatia Str., P.O. Box 159154006 Thessaloniki, Greece 


\section{J. Social Sci., 8 (2): 238-245, 2012}

In Greece, this kind of groups can be spotted in Greek language learning programs for adult immigrants. In these occasions the advisory dimension of the Educator's role is necessary to cover data relevant with the cultural burdens the educated people carry. Consequently, in order to be created a fertile ambience of communication between themselves, it needs to be cultivated the intercultural communication.

The intercultural communication: If we consider that the multiculturalism characterizes the existing situation in the Greek society, what is demanded is to develop an intercultural communication between its parts. For the intercultural communication is a symbolic procedure by which people from different culture create common points (Lustig and Koester, 2009). Taking this as granted, the cross-cultural communication may help to the mitigation of the tense that creates the meeting of people from different parts of the planet as during the connection between the culture and the communication significant chances arise. The allocated goals of the Intercultural Education for Habemas (Govaris, 2000b) are three: the empathy, the critical attitude towards the others and the tolerance of conflicts.

Empathy: As Empathy, it is defined the ability of cognitive and sentimental outlook of "I" to the place of the "Other" with the meaning of acceptance and inclusion of "his" expectations from my behavior towards "him". Through the procedure of empathy we are able to realize more objectively the "other's" attitude and behavior through a critical comparison and potentially the excess ion of our perceptions towards the different (Chatzipanagiotidi, 2009).

In order to understand the meaning of empathy as a goal in the intercultural learning we need to track the "foreigners" representations and the structures of the social class for as long as they mediate not only to the official school knowledge but also to the everyday social speech.

The critical attitude towards the others: The social roles regulate in a great degree our everyday communication because we are receipt or we realize the social parts through their/our social role.

Habemas (Govaris, 2000b) claims that the procedure of socialization should not lead to the uncritical acceptance of the social expectations on behalf of the subjects but to the cultivation of specific abilities such as the critical and the creative playing of social roles in order to be possible the expression of the individuality.

The meaning of this ability for the intercultural education comes especially from the fact that in multicultural societies the subjects counteract as carriers of reformed social identities reproducing by this way the dominant procedures of nation-cultural segregation in the social place and the forms of social injustice that are legalized through these segregations.

The tolerance of conflicts: In every communicative situation are presented conflicts and collisions. The assurance of continuity for a communication presupposes abilities of tolerance of conflicts by the subjects' place. This ability allows the subjects to "tolerate" sentimental uncertainties as well as doubts for their knowledge and to remain capable of communication. The tolerance of conflicts allows the subjects to turn into action the principle for the social equality avoiding the "retreat" in confirmed and clichéd configurations of perception and treatment of the "others". The development of this ability is necessary according to Habemas (Govaris, 2000b) as the intercultural meetings are the most extreme cases of communicative situations because of their dynamic of collisions and doubts.

According to the researchers (Gudykunst, 2003; 2005; Stier, 2006) that are occupied with this specific term the intercultural communication can be succeeded when the below requirements are satisfied:

- Respect to the people that come from different cultures

- Constant and honest attempts to realize the world from another point of view

- Being flexible and open in every new knowledge

- Having wholesome sense of humor

- Acceptance of the dissimilarities and denial to the discriminations

- Approach to the others with wish and open mood for learning

- Genuine interest for the others

- Treatment of the dissimilarities not in terms of subordination but as educational chances

Intercultural education: The intercultural education is appeared as the response to the cultural diversity, is based to the intercultural theory and refers to the body of the methods that aim at the mutual understanding and respect (Damanakis, 2004). The intercultural education has the intention to abolish all the segregating lines between the cultures and aims, with equality and justice, at their mutual acceptance and counteraction.

Affected by anthropology, ethnology and educational sociology, Damanakis (2004) defines three basic principles that govern the intercultural education. 
The principle of cultural equality: The adoption of this principle means serious difficulties because the cultural contention, the conflicts and the cultural hierarchy are especially intense in multicultural societies. The need for equivalent recognition and treatment of two cultures is necessary otherwise the person is placed in front of the dilemma to decide which manners, values and ways of behavior he will adopt and which he will reject. Under this thought lies the danger of absorption that is forwarded by circles that serve directly or indirectly the absorption policy.

Nevertheless, the proclaim of a cultural evidence as functional or not, as useful or not, is the result of evaluation and hierarchy. However, the evaluation and the hierarchy are beyond the sense of the intercultural theory that claims evaluative detachment.

The assumption of "deficit" and "disparity: According to an opinion that is called "the assumption of deficit" the informative chapter of people from lower social levels in comparison to those from middle or upper levels is considered as deficient. According to another opinion that is called "the assumption of disparity" the socio-cultural and language evidence that people from lower social levels carry, the immigrants in our case, are not considered as deficient but as different from those of native people.

The intercultural education adopts the assumption of disparity and aims at the equivalent treatment of the immigrants' language and culture from the education and the culture of the host country. As a result the various student groups can be preserved and cultivated to the framework of a pluralistic educational and social system where they do not need to be equated between themselves.

The principle of equal chances: The recognition and the promotion of the immigrants' language and culture contribute significantly to the improvement of their educational chances. The absorption policy on the other hand and the characterization of a part of the immigrants' informative chapter as dysfunctional, reduce their informative chances and significantly hold back the procedure of a sociopolitical and personal identity acquisition. The school and generally the place of education has to accept the person and give him the chance to develop his abilities and his personality based on his own socio-cultural premises and his own informative chapter.

The acceptance of the principles mentioned above and the effort to structure a pedagogical theory on them, have significant consequences to the science of education as well as to the educational policy.

Intercultural ability: In order to be effective on his educational work, the Educator should be able to control complex problems that the susceptible social groups or the groups of different cultural level face. This ability is directly related to the development of his intercultural ability.

When we talk about intercultural ability we mean the sum of social skills that allow people to recognize and accept the disparity (Nikolaou, 2005) by this way, the pluralistic cultural complex of a class of adults makes necessary the development of intercultural ability on behalf of the Educator. The Educator of Adults, that has developed intercultural ability, is able to manipulate creatively the various evidence that are related with it, to develop new strategies for functional communication and often to readjust previous opinions and attitudes.

Developing this specific ability the Adult Educator contributes to the mitigation of the tense that is created by the meeting of people from different cultures, in parallel to the designation of chances from their acquaintance (Nikolaou, 2005) through a constant and fertile counteraction.

Naturally, for the successful development of the intercultural ability, it needs to be taken into account some allocated factors that invoke to skills, knowledge and attitudes from his point of view (Pedersen and Ivey, 1993). Moreover, for the occasion that the Educator of adults is occupied with immigrants, the parameters mentioned above need to agree with the standard of intercultural ability that is mentioned above. Generally, the factors that are needed for the success of the Educator of adults as intercultural consultant can be summed up into three: the intercultural knowledge, the intercultural realization and the intercultural skill.

The intercultural knowledge refers to realization of the social role the immigrants play. The Adults' Educator that has this cross-cultural knowledge is able to know enough things for their culture and to realize the difficulties and obstacles that face the people that come from other countries.

The intercultural realization lays to the awareness of the person for his own cultural background and his own cultural values and beliefs. The educator that has intercultural realization feels comfortably and accepts the cultural differences that arise between him and his students. He has the ability to judge correctly a situation from his own point of view and from the point of view of people from other cultures. If the knowledge is inefficient for his own culture, then the difficulties he meets when he tries to get into the "other's "position are more intense.

The intercultural skills refer to the development of a repertoire of verbal and non-verbal communication suitable for various different cultural frameworks. The Educator that has intercultural skills is able to send and 


\section{J. Social Sci., 8 (2): 238-245, 2012}

to accept with a concrete way the signals mentioned above to and from the culturally "different" students. Moreover, thanks to his cross-cultural skills an Educator has the flexibility to adjust a lesson for the benefit of the culturally different educated group, focusing to its needs (Pedersen and Ivey, 1993)

For an immigrant Adult Educator the theoretical knowledge, the skills and the scientific brilliance for matters of Intercultural Education are necessary in order to correspond to a multicultural class

During the learning procedure in a multicultural class, the wary teacher, who according to the Adult Education theory acts as a facilitator in the class for the knowledge acquisition (Kapsalis and Papastamatis, 2002) needs to take advantage of the intercultural dimension of every tutored object. It is beneficial not to lose the chance to orientate the goals of the intercultural education, as they are defined above, without staying focused to the idea that the only challenge to the occasion of a multicultural class is the learning of the tutored object.

We can consider that the intercultural dimension to the role of immigrants Adult Educator is not only a part o f a program but a cohesive approach. For this reason the immigrant Adult Educator needs to.

To mitigate the negative feelings that arise from the discrimination of the tutored because of the distinctive racial and cultural characteristics and to promote their abilities in order to correspond to the lesson and to achieve high performance.

To promote the awareness of the history, the culture and the forms of all the national and racial groups.

To enhance the self-esteem, the knowledge and the skills of the people to the degree they can evaluate, realize and recognize equivalently the cultural differences (Gay, 2002) By this way, they can be motivated successfully in their national culture, in the dominant culture but and to others (Charitos, 2011).

The challenges of the adult educator of immigrants as intercultural consultant: The interpersonal relationships are integrated to the advisory role the Educator undertakes and for this reason they are unavoidable the challenges that arise and are defined as troublesome.

In the multinational classes of adults' immigrants, the challenges that an Educator face, come to a great degree from the cultural background of the tutored. Regularly, the Educator has to face himself as he needs to expel the stereotypes that he has about people of some countries. But the challenges to the framework of this role do not always start by him. Many times, challenge is the treatment of prejudiced behavior and attitude from the tutored towards him. Nevertheless, the challenges that arise from a multicultural meeting do not always demand the spanning of the relationship between the tutored and the Educator, but the Educator often plays the role of the mediator for the sanitation of the relationships between the tutored.

Below, we could see situations that are developed from the Educator's part towards the tutored, others that start from the tutored and address to the Educator and others that inevitably happen between the tutored. In all these three occasions, the situations that we are going to elaborate and to which we are going to find ways of treatment, independently from their source, are a challenge for the Educator that should apply revocation practices.

The stereotypes of the educator in a multicultural class: To the challenges that the Adults' Educator has to face as intercultural consultant is included the ways of approach towards the tutored immigrant. The stereotypes and the prejudices are things that undoubtedly characterize every person and consequently the Educator is not the exception. We often develop stereotypical behavior that we do not admit openly. The stereotypes that all of us carry with, usually have deep and multilateral sociopolitical and cultural origins (Kalatzi-Azizi et al., 1996). Consequently, the contact with different cultures from the Educator's part may dig up stereotypical beliefs that he has formed for people that come from specific countries.

Suggestion of treatment: Our suggestion for the treatment of this specific challenge of course is not the "revocation" of stereotypes and prejudices. This happens not because something like that is desired in this specific occasion but because we consider that something like that would be utopian. If we accept as the definition of the stereotype the artificial ideas, images and beliefs that exist in our mind for specific people, social groups and social categories (Papatsoumas and Chios, 2006) we can realize that the stereotypes are especially firm beliefs. Consequently, it would be more correct to talk more about their reconsideration and not so much about their riddance. The reconsideration would be attempted through the acquaintance with the "other" culture and under the prerequisite of mutual cultural respect. If The Adults' Educator bumps evidence from various sources and from the immigrants they about their origin country, he may make the first step in order to redefine the perceptions and beliefs for people coming from specific countries. So, the Educator through his advisory role in order not to be stereotypical should constantly remind to himself that every person is unique and different (Malikiosi-Loizou, 2008).

The negative attitude of the tutored immigrants towards the Educator, as a representative of the natives: Nother powerful challenge that the Adult 


\section{J. Social Sci., 8 (2): 238-245, 2012}

Educators might face into a multicultural class are the negative experiences the immigrants might have accepted coming to Greece from a native group and are related to phenomena of racism and xenophobia. When the Adult Educator carries the same cultural identity with that native group and as part of that group, he might bring into the immigrant's mind the difficulties and problems has faced trying to become a part of the Greek society. We could claim that in this occasion the tutored immigrant creates a causative relationship between the Educator's cultural identity and the Greek's cultural identity that had caused the difficulties during his attempts for inclusion. Practically, the Educator is coincided by the immigrant with the "Greek" that hindered his adjustment procedure to the host country (Haslett and Ogilvie, 1988). In these occasions the Educator might experience bigger tension, as he feels co-responsible for matters of social exclusion (Themeli, 2010).

Suggestion of treatment: This challenge could be faced by the Educator through the practices of empathy. As mentioned, Empathy it is defined the ability of cognitive and sentimental outlook of "I" to the place of the "Other" (Chatzipanagiotidi, 2009). When the "other" belongs to a different cultural background the Educator has to adopt a behavior adjusted to the idea of cross-cultural empathy. This term describes the ability that the Educator has to the framework of his role as consultant to realize and communicate with subjects that occupy the tutored from their cultural aspect (Ridley, 2005; Malikiosi-Loizou, 2008). If the Educator, in the occasions that he feels a negative mood towards him because of his cultural identity, manages to realize more objectively the "other's" attitudes and positions getting into his place, showing sympathy, respect, active listening and compassionate of his difficulties and problems, a mood of trust and security will be succeeded (Themeli, 2010) able to sideline the negative experiences that may exist from the Greek's image. Besides, it is considered that the skills implied to the cultural empathy are taught and they are not inherent.

Moreover, it is claimed (Haslet and Ogilivie, 1988) that something like that could be succeeded through feedback, from the Educator's side, of positive experiences. In every instance that the Educator indicates narrations of the tutored about positive experiences from Greeks, he can apply feedback practices to boost his words in order to reshape the negative image that immigrants have shaped. This feedback can be expressed through many forms, verbal and non-verbal and can be provided either directly or after a while since the moment the message was transmitted.
Another factor that plays an important role to the improvement or even to the elimination of the negative attitude towards the carrier of Greek identity is the humor (Smith and Bond, 2005). Humor is a special kind of communication as the most researchers that are occupied with it until today have not achieved to conclude to a universally recognized definition. According to Hay (2001) humor is anything the speaker wants to present as funny stressing however, its subjective character. Through humor a friendly mood is created that cuts the threat to pieces, promotes the communication and contributes to the creation of a more productive environment. Furthermore, we can consider that it is a very influential connecting power for the social contacts of many cultural groups. However, the Educator should not ignore that because of the subjective evidence that humor serves, there are differences among the cultural groups concerning its content as well as its significance by them (Smith and Bond, 2005).

Difficulties in the definition of multicultural forms of communication from the Educator's side: In a multicultural class of adults the different cultural references make difficult the definition of miscellaneous forms of communication (Papachristos, 2007). There are not few the times that the difficulties reach the limits of misunderstanding and/ or misconception about the "other's" words. The verbal as long as the cultural differences of the participants are frequently unclear from people of other cultures and as a result problems are created during the communication (Papachristos, 2007).

For Instance, there is category of cultural groups that feels awkward in a wide range of situations in comparison to people from other cultural groups. The first category refers to collective cultures and includes civilizations from Asia, Africa and some from the southern Europe. The second category refers to individualistic and includes people from countries such as America and some of the western European countries (Chatzichristou, 2008). In the collective civilizations the demonstrations and the expressivity are deteriorated to a level of verbal and non-verbal behavior. Moreover, the person in this occasion is defined from his relationship with the "others". On the other side, in the individualistic civilizations dominates the perception that every person is an independent being that distinguishes for some internal characteristics and behaves according to them (Chatzichristou, 2008).

So, we realize that there are evidences that are defined or arise from the cultural background of the person and differentiate the way he communicates with his environment. Consequently, there are not few the times that the expressions, verbal or non, of one person 


\section{J. Social Sci., 8 (2): 238-245, 2012}

are received differently from the other having as a result a difficulty to understand one another.

Suggestion of treatment: In relation to the difficulties during the communication, because not only of the difficulties during the communication among the tutored but also because of the different behavior of those who come from different cultures, the Educator may cultivate particular practices. He needs to enrich his knowledge about basic national-cultural evidence that refer so to the language as to the non- verbal behavior of his tutored. Particularly, in relation to the non-verbal signals of communication, that is more luckily to be misunderstood and to create difficulties in the communication, the Educator's role demands the development of consideration.

Conflicts inside a multicultural group: An important aspect to the advisory role of the Adult Educators are matters related to the dynamic of the group and to the way the conflicts inside the group are solved. It is a fact that such kind of matters may happen to any kind of group independent of its composition. However, we consider that in a group of tutored, where people of various cultures take part, the challenge is more intense for the Educator in order to manipulate it. The reason is the conflicts that may happen among them and come from stereotypical perceptions based to the cultural background of the tutored. As it was aforementioned the prejudices and the stereotypes occupy unavoidably a part of a person's perceptions. However, the immigrant experiences a cultural shock, when coming to another new country.

This cultural shock starts when the immigrant establishes to the new environment and is defined as the reason for lack of balance from the moment the immigrants gets into contact with new cultural and social data (Berry, 2001). The cultural shock is intensified even more when the participant in an immigrants' class has to be accepted, not only himself but his cultural identity also, not only from native parts of the group but from foreigners also.

Suggestion of treatment: The Adult Educator even if he does not have any special education for the subjects mentioned above, it is important to promote with a democratic character the equivalency to his relationships with the tutored. With the cultivation inside the classroom of a mood of partnership and with the application of experiential methods and methods of teamwork tutoring he discourages a clan's formation. Additionally, the Educator can contribute to the revocation of conflicts that are created into a multicultural group finding a common ground among the parts of the cultures without losing their cultural identity (Pedersen, 2000). Furthermore, as each person's culture is perceived differently from members of other cultures, it is beneficial the Educator to recognize the relationships among the cultural groups in order to manipulate them suitably (Papachristos, 2007). The development of democratic attitude, the emergence of respective values towards the culturally different tutored and the ability of placement and viewing of things from various sides (Krivas, 2009) we can consider to be the solution for the balance in the relationships that are formed and are frequently disrupted because of specific factors.

\section{MATERIALS AND METHODS}

The methodology that we used was the literature review. The base material of our study was mainly the direct sources, such as books and articles that deal with this aspect of the Adult Educator. We chose this structure because it was considered the most appropriate, clearer and informed in order to show the particular role undertaken by the Adult Educator when he is in multicultural class.

\section{RESULTS}

The results of the literature research has shown that in a multicultural educational meeting with educational features, the teacher faces many challenges which he needs to repeal. However, the challenges do not always call the Educator to repeal them, but sometimes he simply helps the students in order to remove the negative situations that the students experience because of a different cultural identity. On the other hand, the acquaintance with the culture of the "other", the feedback of positive experiences associated with the image of the "other", the application of techniques for development of empathy, the use of humor, the cultural enrichment of knowledge and promoting democratic culture in the class are elements that we believe can help the Adult Educator of immigrants to respond to the needs of the learners. Applying these techniques, the Adult Educator revises the stereotypes that he might has initially, he tries to remove the negative image that the immigrant students may have for the Greek, he interprets correctly the multicultural forms of communication and prevents conflicts within the multicultural team. So, because these parameters don't relate to the cognitive part of the Educator, we set him as Multicultural Consultant. 


\section{DISCUSSION}

The special cultural evidence of adult immigrants in an educational program is an integral piece of their identity and influence the whole procedure of adjustment in the class framework. The adjustment to a new cultural environment demands many times incorporation not only of different but also of contradictory cultural principles. For this reason, it is essential the sensitization of the Adult Educator who will take up a multicultural class. The complexity of the situations that are perceived as challenges from his part are directly connected with the development of his intercultural role. Consequently, the Adult Educator's role as intercultural consultant has the ability not only to readjust the presence of the tutored immigrant inside the classroom but also to contribute to the redefinition of experiences and perceptions of the culturally different tutored and of his. The results of the Adult Educator's intercultural practices do not influence the participants only to the class framework but they influence their life outside of the classroom, as through intercultural techniques there are structured attitudes and behaviors that are cultivated more to an individual social framework. Concluding, taking as granted the above, to the importance of undertaking and development of the role of the cross-cultural consultant from the Adult Educator.

\section{CONCLUSION}

According to the literature review, we realize that the students have a very important role in Adult Education. In our case, because the adult students are culturally different from each other, we find that the Educator's role is directly affected in the class. Therefore, the Educator is also affected as a person. Our research underlines an interactive relationship which exists between the Educator and his group, highlighting the benefits from the Adult Education. Specifically, the Adult Education can transform opinions and attitudes of all involved members, it can reconsider conditions and situations and it can enrich perceptions. Actually, isn't it the real purpose of the Education?

\section{REFERENCES}

Berry, J.W., 2001. A Psychology of Immigration. J. Soc. Issues, 57: 615-631. DOI: 10.1111/00224537.00231

Charitos, V., 2011. The intercultural approach in the education of students of pedagogical departments. $\mathrm{PhD}$ Thesis, Thessaloniki.
Chatzichristou, C., 2008. Social and Emotional treatment in school. Primary Education, Typothito, Athens.

Chatzipanagiotidi, A., 2009. The culture in teaching of foreign language, the of greek language. University of West Macedonia, Florina (Greece).

Damanakis, M., 2004. the education of repatriates and foreigners students in Greece-intercultural approach. Gutenberg, Athens.

Gay, G., 2002. Preparing for culturally responsive teaching. J. Teacher Educ., 53: 106-116.

Govaris, C., 2000a. Intercultural Education and the dilemma of "multicultural differences". J. Filologiki, 109: 78-82.

Govaris, C., 2000b. Introducing to the intercultural education. Atrapos, Athens.

Gudykunst, W.B., 2003. Cross-Cultural and Intercultural Communication. 1st Edn., Sage Publ., Thousand Oaks, ISBN-10: 0761929002, pp: 302.

Gudykunst, W.B., 2005. Theories of intercultural communication I. China Media Res., 1: 61-75.

Haslett, B. and J. Ogilvie, 1988. Feedback processes in small groups. Small Group Communication: A reader, Dubuque, IA, Brown.

Hay, J., 2001. The pragmatics of humor support. Humor: Int. J. Humor Res., 14: 55-82.

Kalatzi-Azizi, A., A., Zoniou-Sideri and A.,Vlachou, 1996. Prejudices, stereotypes: making and facing. Ministry of Education and Long Life Learning, Athens.

Kapsalis, A. and A., Papastamatis, 2002. Adult Education: General Introductory Issues (Vol. A'). University of Makedonia, Thessaloniki.

Krivas, S., 2009. Values and Development for career through the intercultural counseling: The establishment of a model. Inspect. Counsel. Orientat., 50-51: 58-65.

Lustig, M.W. and J. Koester, 2009. Intercultural Competence: Interpersonal Communication Across Cultures. 6th Edn., Pearson/Allyn and Bacon, Boston, ISBN-10: 0205595758, pp: 388.

Malikiosi-Loizou, M., 2008. The multicultural dimension of the empathy. J. Psycol., 15: 1-15.

Nikolaou, G., 2005. Intercultural teaching: The new enviroment, the fundamentals. Ellinikia Grammata, Athens.

Papachristos, K., 2007. Cross-culturing counseling and gender. Scanning the aspects of intercultural consultant. Proceedings of 4th Hellenic Conference "Equal School for Unequal Children" Athens, May 4-6, Greek Institute of Applied Pedagogy and Education.

Papatsoumas, N. and A. Chios, 2006. "We" and the "Others" from the existance to coexistance: prejudice, xenofovia-resistance. The example of a research. Thessaloniki, Lithografia. 
Pedersen, P., 2000. A Handbook for Developing Multicultural Awareness. 3rd Edn., American Counseling Association, Alexandria, VA., ISBN: 155620177X, pp: 230.

Pedersen, P.B. and A. Ivey, 1993. Culture-Centered Counseling and Interviewing Skills: A Practical Guide. 1st Edn., Praeger, Westport, ISBN-10: 0275946681, pp: 209.

Ridley, C.R., 2005. Overcoming Unintentional Racism in Counseling and Therapy: A Practitioner's Guide to Intentional Intervention. 2nd Edn., Sage Publications, Thousand Oaks, ISBN-10: 0761919813, pp: 272.
Smith, P.B. and M. Bond, 2005. The intercultural social psycology. Ellinika Grammata, Athens.

Stier, J., 2006. Internationalisation, intercultural communication and intercultural competence. J. Int. Commun., 11: 20-12.

Themeli, O., 2010. Training of socially sesitive groups' educators and members. Ministry of Education and Long Life Learning, Athens. 